\title{
Comment on "Hassan W, David J (2014) Effect of lead pollution on soil microbiological index under spinach (Spinacia oleracea L.) cultivation. J Soils Sediments 14: 44-59"
}

\author{
Philip N. Owens • Zhihong Xu
}

Received: 26 March 2014 / Accepted: 2 April 2014 / Published online: 15 April 2014

(C) Springer-Verlag Berlin Heidelberg 2014

The Editors-in-Chief would like to alert readers to the following article published in Journal of Soils and Sediments:

Effect of lead pollution on soil microbiological index under spinach (Spinacia oleracea L.) cultivation. DOI 10.1007/ s11368-013-0802-3 January 2014, Volume 14, Issue 1, pp 44-59, Waseem Hassan, Julie David

Since the paper by Hassan and David (2014) was published in the Journal of Soils and Sediments, it has come to our attention that the research project is very similar to that of an MSc project authored by Mr Idrees Haider in 2009 at PMAS Arid Agriculture University, Rawalpindi, Pakistan. The experimental design of Hassan and David (2014) appears to be identical to that of Haider (2009), but for a new field site in the same country. Mr Idrees Haider and Mr Waseem Hassan were MSc students at the same institution (PMAS Arid Agriculture University, Rawalpindi, Punjab, Pakistan). Mr Waseem Hassan completed his thesis in 2008 on a research study independent of the data presented in his paper, Hassan and David (2014). Mr Haider's MSc project was completed and published in 2009 and was titled "Effect of lead on soil microbial biomass and enzymes activity under spinach cultivation".

We have followed-up with the authors, their MSc supervisor and department chair to ascertain whether there was any inappropriate overlap in the research methodology, data analysis and publication, but have not been able to come to a conclusion based on the responses provided to us. The respective authors are pursuing this matter through other avenues.

P. N. Owens $(\square)$

Environmental Sciences Program, University of Northern British

Columbia, 3333 University Way, Prince George, British

Columbia V2N4Z9, Canada

e-mail: owensp@unbc.ca

\section{Z. Xu $(\bowtie)$}

School of Biomolecular and Physical Sciences, Griffith University,

170 Kessels Road, Nathan, Queensland 4111, Australia

e-mail: zhihong.xu@griffith.edu.au 